\title{
A case report of primary pulmonary artery intimal sarcoma
}

\author{
Xiaofang Bai and Litao Ruan * (1)
}

\begin{abstract}
Background: Pulmonary artery intimal sarcoma (PAS) is a very rare disease, its prevalence is about $0.001-0.003 \%$. PAS is often misdiagnosed as acute or chronic pulmonary thromboembolism due to its clinical presentation and radiological findings. Thus, early diagnosis is very crucial and may improve patient outcome.

Case presentation: Here, we report a case in a Chinese male where the symptom presentation was episodes of shortness of breath. Transthoracic echocardiography showed a solid mass in the pulmonary valve orifice, which was demonstrated to be a pulmonary artery intimal sarcoma diagnosed by histopathology. In this case, the initial differential diagnosis included pulmonary embolism. Because the initial symptom of primary pulmonary artery sarcoma is extremely similar to the pulmonary embolism, half of them may be misdiagnosed as pulmonary embolism. Imaging studies are very helpful. Ultrasound and CT are the best due to their resolution and ability to assess the relationship of the mass with the surrounding structures. The final diagnosis is mostly made after surgical excision and this is the most effective treatment. At the same time, radiotherapy and chemotherapy after surgery is also an adjuvant treatment.
\end{abstract}

Conclusion: We report a very rare case of pulmonary artery intimal sarcoma. Due to late diagnosis and delayed treatment in this case, the patient displayed a poor prognostic. Early diagnosis and right treatment can improve the prognosis of PAS and optimize overall health.

Keywords: Pulmonary artery intimal sarcoma, Echocardiography, Adult

\section{Background}

Angiosarcoma is a malignant tumor derived from vascular endothelial cells. It has low incidences. It can occur in the skin, breast, spine, small intestine, spleen, kidney and so on, accounting for about $2 \%$ of all soft tissue sarcoma. Pulmonary artery sarcoma belongs to one of angiosarcoma, which originates from primitive pluripotent interstitial cells with multiple differentiation ability. Pulmonary artery sarcoma can originate from the left and right pulmonary arteries and intimal layer of pulmonary arteries, forming a tumor growing in the nodular cavity,

*Correspondence: ruanlitao@163.com

The Department of Ultrasound Medicine, The First Affiliated Hospital, Xi'an Jiaotong University, No. 277, Yanta West Road, Xi'an 710061, Shaanxi, China or spreading along the intimal surface, and retrograde can involve the pulmonary valve and the right ventricle. It can be found in pulmonary artery trunk or unilateral or bilateral pulmonary artery [1].

Pulmonary artery intimal sarcomas are rare. Nonetheless, approximately 400 cases of pulmonary artery intimal sarcomas have been reported in the literature up to the year 2021. Most of them were published by case reports. Because the primary pulmonary artery intimal sarcomas were often misdiagnosed, the incidence of it may be underestimated.

\section{Case presentation}

A 72-year-old man was admitted with shortness of breath for more than 1 year after the activity and then had hemoptysis for 1 week. The patient has a history original author(s) and the source, provide a link to the Creative Commons licence, and indicate if changes were made. The images or other third party material in this article are included in the article's Creative Commons licence, unless indicated otherwise in a credit line to the material. If material is not included in the article's Creative Commons licence and your intended use is not permitted by statutory regulation or exceeds the permitted use, you will need to obtain permission directly from the copyright holder. To view a copy of this licence, visit http://creativecommons.org/licenses/by/4.0/. The Creative Commons Public Domain Dedication waiver (http://creativeco mmons.org/publicdomain/zero/1.0/) applies to the data made available in this article, unless otherwise stated in a credit line to the data. 
of dermatophytosis for 4 years and never-treated, smoking more than 20 years cigarettes 3 per day and quitting smoking for 6 months, drinking for more than 10 years. On physical examination, her bilateral zygomatic and lips had cyanosis, hepatic jugular venous reflux sign was positive. Mild systolic murmur of grade $2 / 6$ could be heard in the auscultation area of pulmonary valve and peripheral oxygen saturation was $97 \%$ while breathing ambient air. Two-dimensional transthoracic echocardiography showed a solid mass was detected at the pulmonary valve orifice, showing moderate-to-strong echo. Its outline was clear, and the internal echo was uniform, with the size of about $57 \mathrm{~mm} \times 36 \mathrm{~mm}$. It was attached to the pulmonary valve orifice, part of which was located in the right ventricular outflow tract, and part in the main pulmonary artery. There was no obvious motion, causing obvious stenosis of the pulmonary valve orifice (Fig. 1, arrows). The right atrium and right ventricle were enlarged, and the interventricular septum shifted to the left ventricle, showing "D" sign (Fig. 2). Color Doppler flow imaging showed moderate regurgitation in tricuspid valve with regurgitation area of $8.8 \mathrm{~cm}^{2}$ (Fig. 3), regurgitation velocity of $420 \mathrm{~cm} / \mathrm{s}$ and PG of $70 \mathrm{mmHg}$ (Fig. 4). Computed tomography angiography (CTA) findings of superior vena cava: right ventricular and the root of pulmonary artery has low-density imaging, considering that it is thrombosis, neoplastic lesions are not excluded (Fig. 5, arrows). The patient underwent surgery, which showed pulmonary valve has solid occupying lesions, pale yellow, soft, nonenveloped, wrapping of the pulmonary valve leaflet, adhesion of the posterior wall of pulmonary valve, clipping the mass along the posterior wall of the pulmonary valve, the size of the mass is about $6.0 \mathrm{~cm} \times 4.5 \mathrm{~cm}$ (Figs. 6, 7). Cardiac

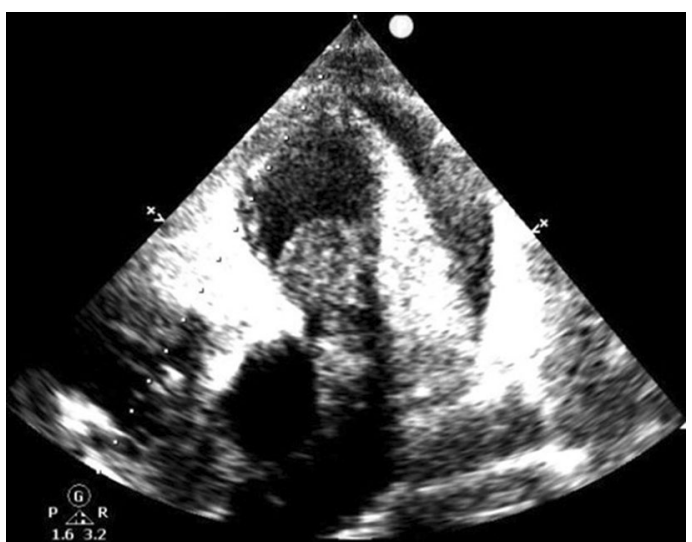

Fig. 1 Long axis of pulmonary artery of transthoracic echocardiography. Arrow indicates the location of the lesion

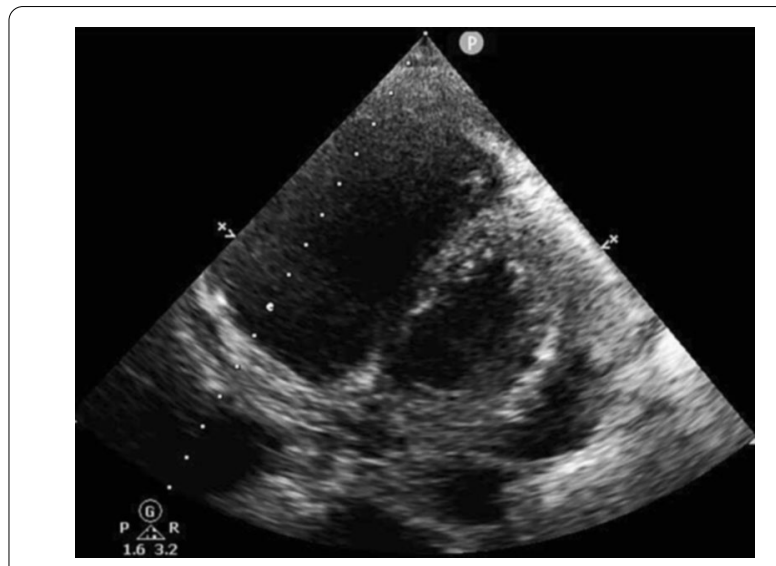

Fig. 2 Short axis of left ventricular of transthoracic echocardiography

surgeons explored that the posterior wall is very thin, fresh autologous pericardium to reconstruct the pulmonary valve. Continuous observation intraoperative by transoesophageal echocardiography. Postoperative transoesophageal echocardiography demonstrated no obvious abnormalities in the pulmonary arteries. Doppler examination showed a maximum flow velocity of $110 \mathrm{~cm} / \mathrm{s}$; color Doppler flow imaging (CDFI) displayed there was no stenosis in the pulmonary arteries. The final pathological diagnosis is Pulmonary artery endometrial sarcoma (Fig. 8). The lesions presented three regions under the microscope: including necrotic regions, sparse region and intensive areas. Tumor cells grow in solid neoplasm, invade from pulmonary artery intima to adventitia, most of the tumor cells are spindle cells, it is very obvious in heteromorphism. Collagen presents predominantly in the interstitial matrix, also bone matrix visible, nuclear compartmentalization and necroptosis is frequent. An immunohistochemical analysis showed that $C D$ vimentin-positive

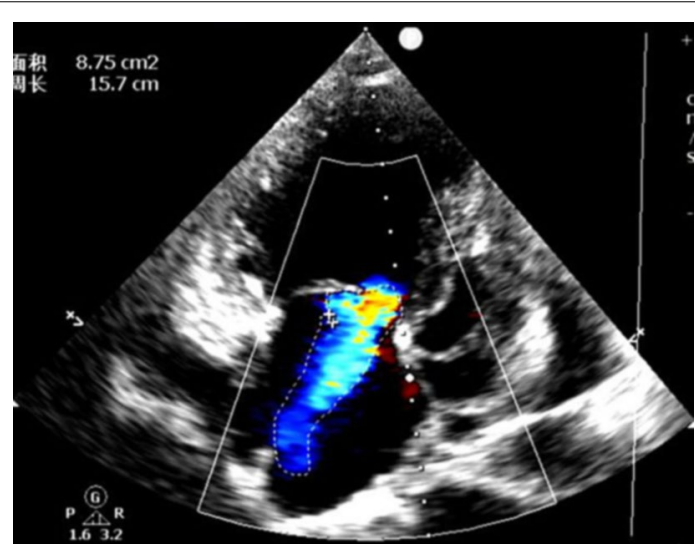

Fig. 3 Severe tricuspid regurgitation on color flow Doppler 


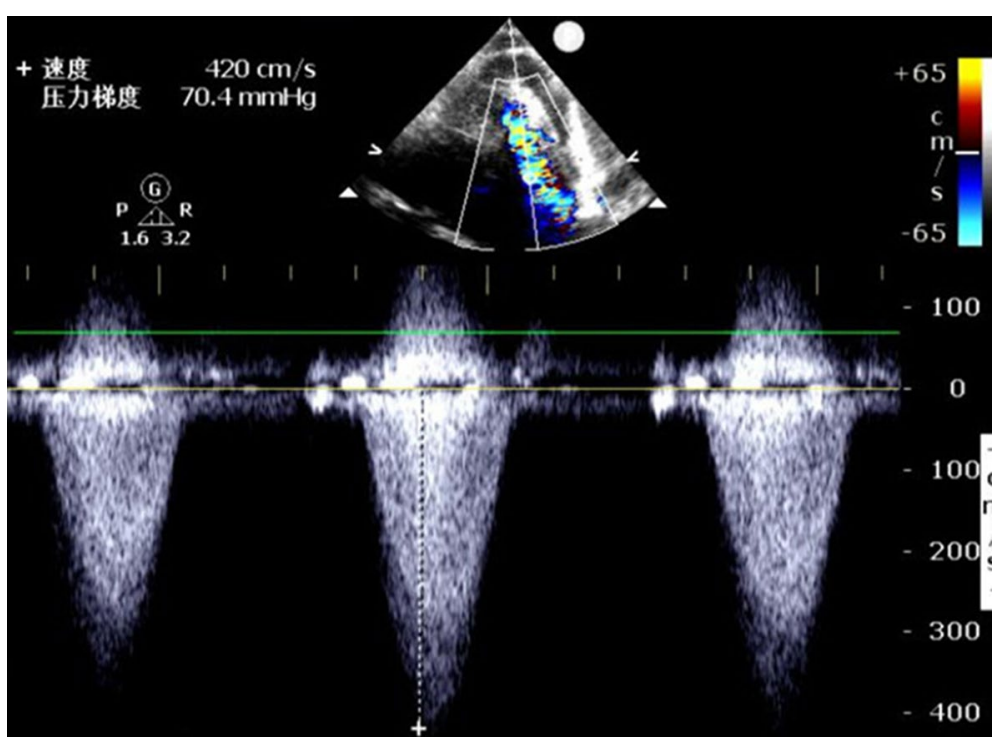

Fig. 4 Severe tricuspid regurgitation on spectral Doppler

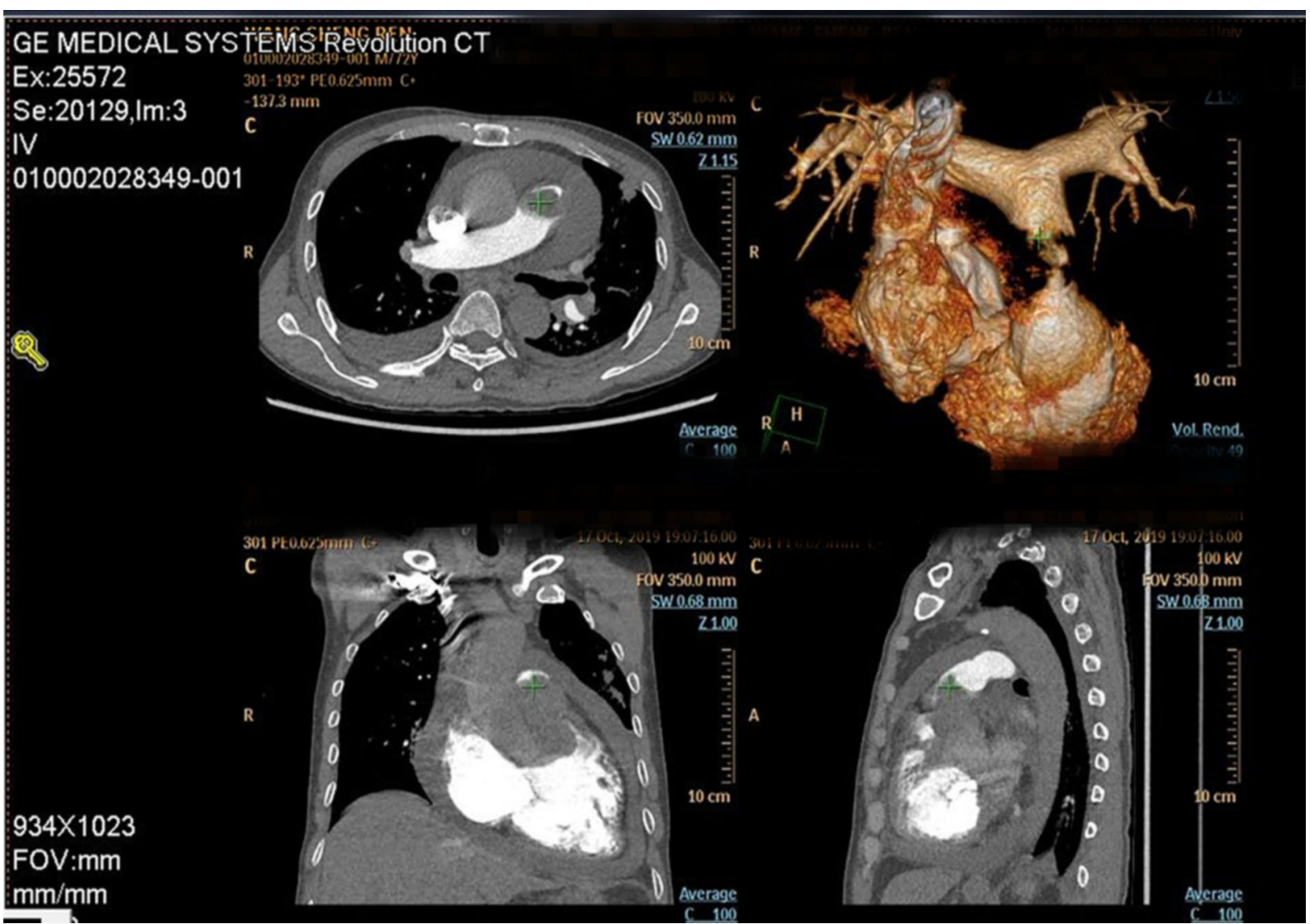

Fig. 5 Computed tomography angiography (CTA) findings of superior vena cava images acquired in multiple planes. Arrow indicates the location of the lesion 


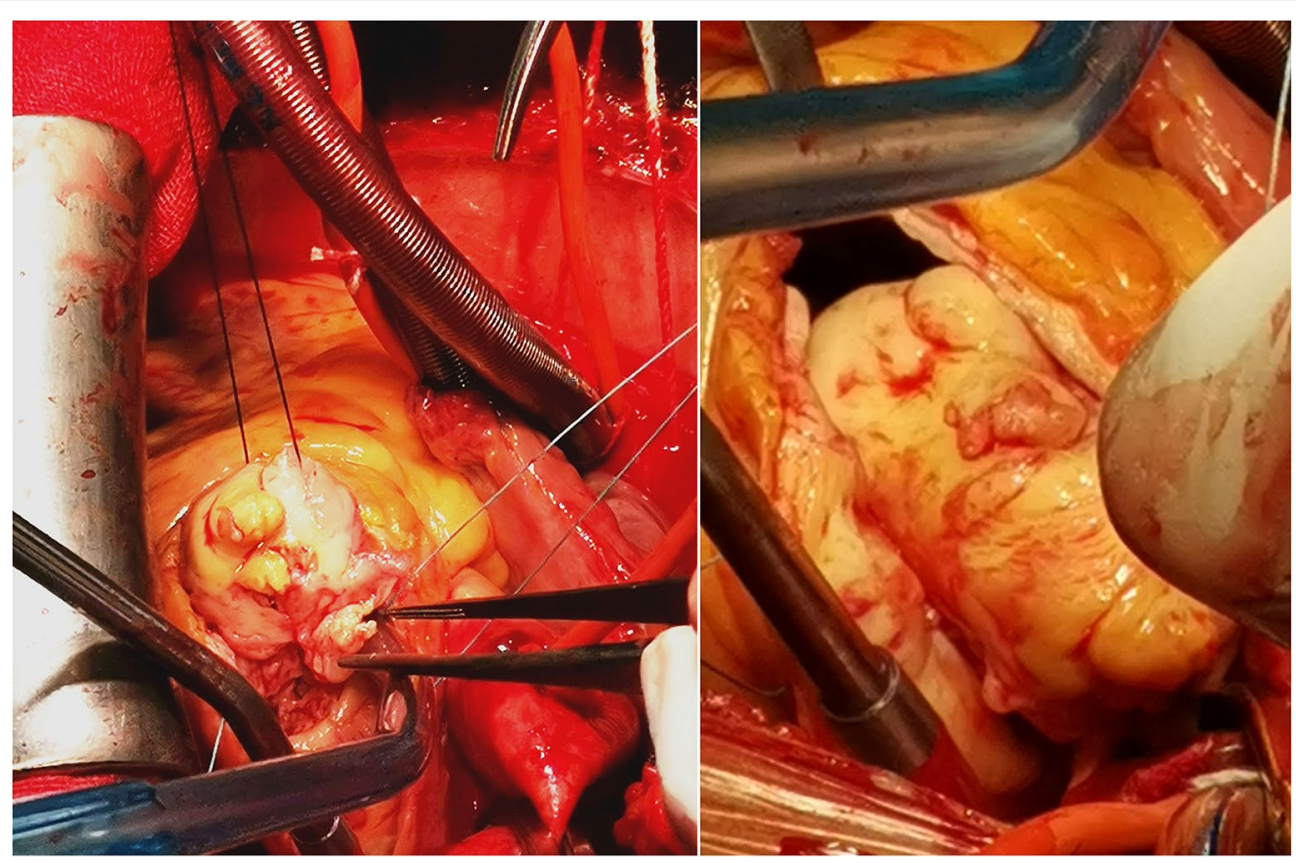

Fig. 6 The intraoperative images. Operative view of the primary pulmonary artery intimal sarcoma
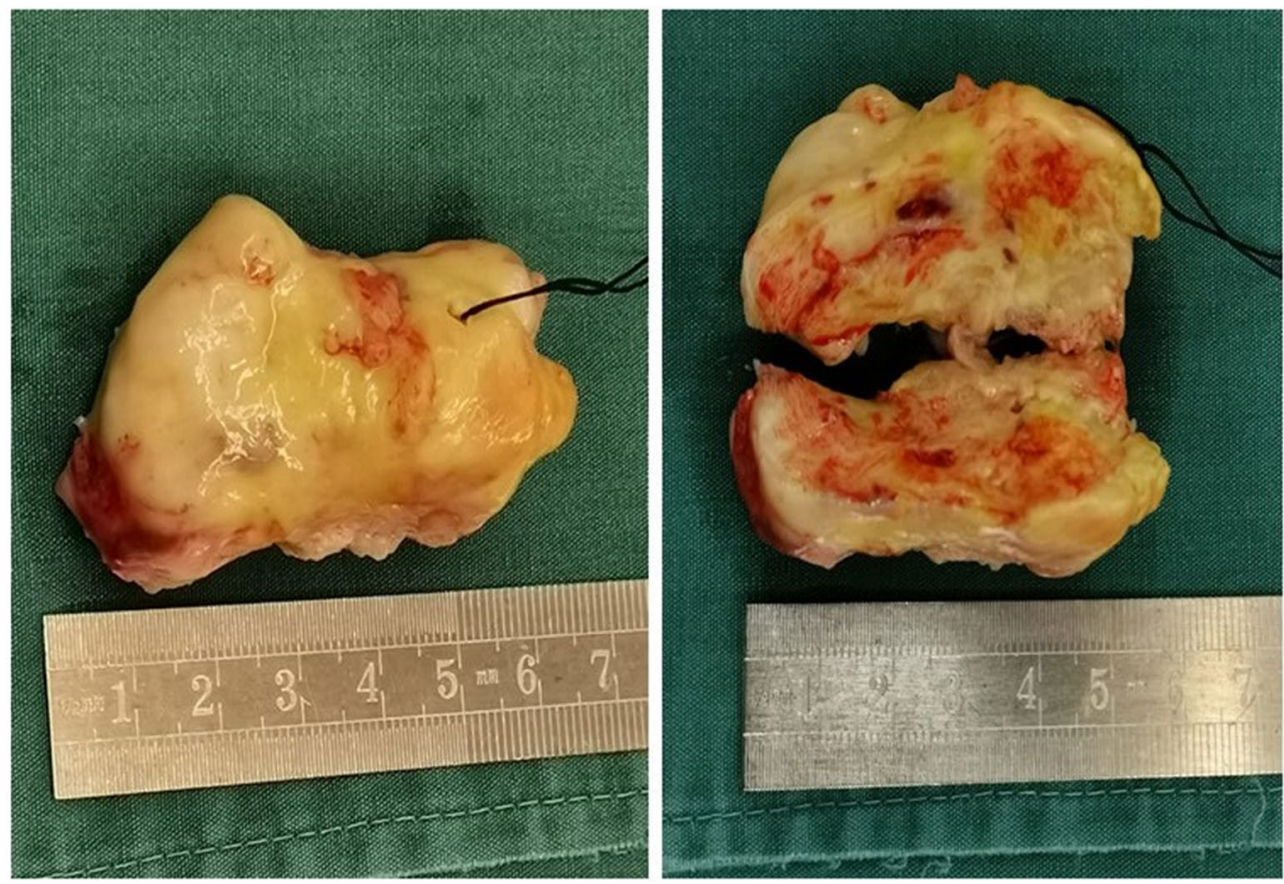

Fig. 7 Gross specimen of primary pulmonary artery intimal sarcoma

and $\alpha$-smooth muscle actin-positive, desmin-negative, CD34-negative, CD31-negative, F8-negative, Stat6negative, Ki67 $(+10 \%)$, S100-negative, SOX10-negative, TLE1-negative, CK-negative, EMA-negative. A further treatment for this patient after cardiac surgery was carried on in the cardiac intensive care. Persistent hypoxemia could not correct after giving various 


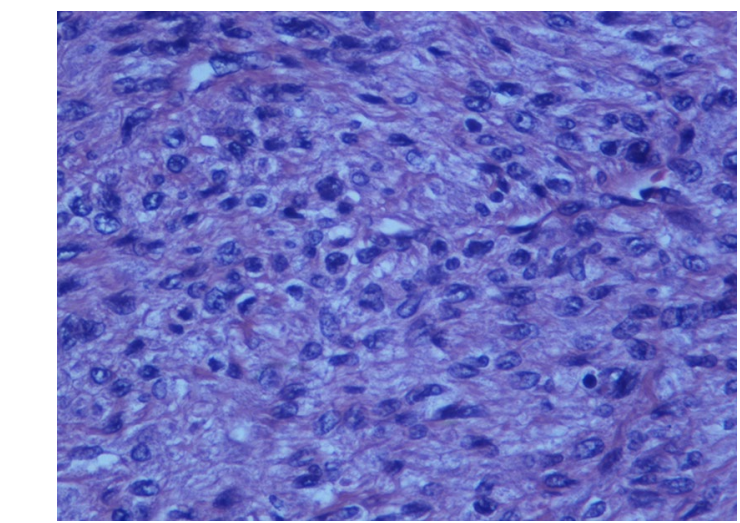

Fig. 8 Histopathology of primary pulmonary artery intimal sarcoma

intravenous drugs. The patient died in the fifth day after cardiac surgery.

\section{Discussion and conclusions Epidemiology}

Large artery endometrial stromal sarcoma is a rare tumor; it is concurrently found in the vein, pulmonary artery, aorta and its branches, pulmonary artery valve, coronary artery, carotid, iliac artery, femoral artery. The incidence of pulmonary artery intimal sarcoma is about $0.001-0.003 \%$. It was first reported by doctor of Mandelstamml in autopsy. The diseases can occur in different age periods, the youngest is 2 months, the oldest is 89 years old, and the average age is about $45-54$ years [2]

\section{Histology and pathology}

The correct diagnosis of PAS is based on the pathological examination. According to the origins of the cells, it can be divided into two types, including endometrial type and wall type (originating from intima-media or the outer membrane). Most of the primary sarcoma of aortic and pulmonary artery is endometrial type, arising in pluripotent hematopoietic stem cells of intimal, Conforming to myofibroblastic tumor, with different cell differentiation of different cells. The histological patterns of this tumor ranges from undifferentiated round cell to spindle cell in the light microscope, ten subtypes of this has been reported at least morphologically, including undifferentiated sarcoma, leiomyosarcoma, rhabdomyosarcoma, chondrosarcoma, osteosarcoma, malignant phyllodes tumor, fibrosarcoma, myxosarcoma, angiosarcoma, malignant fibrous histiocytoma. Most of the pulmonary artery intimal sarcoma is not easy to classify, it is briefly defined as intimal sarcoma or undifferentiated sarcoma [3].

\section{Clinical presentation}

PAS may occur in the main pulmonary artery or in the left and right pulmonary arteries, extending to the distal pulmonary artery. The clinical manifestations were similar to those of pulmonary hypertension and right cardiac insufficiency. In medical imaging, it is easy to be confused with pulmonary arteritis with thrombosis, giant pulmonary thromboembolism and other pulmonary vascular diseases. Common symptoms involve dyspnea, chest pain or back pain, cough, fever, weight loss, hemoptysis, syncope and asthenia [4-6].

\section{Diagnostic approach}

In patients suspected of pulmonary thromboembolism, when radiography shows unilateral pulmonary artery dilatation, persistent soft tissue filling pulmonary artery, pulmonary mass after anticoagulant and thrombolytic therapy, ultrasound found that the pulmonary artery dilatation, irregular mass, uneven echo, lobular shape, extraluminal invasion, all highly suggested the disease. Color Doppler flow imaging shows the relationship between pulmonary artery sarcoma and pulmonary artery and left and right pulmonary arteries in real time. Two-dimensional ultrasound imaging can show the heterogeneous parenchymal echo of pulmonary artery sarcoma, which is helpful to distinguish it from the homogeneous and weak echo of fresh thrombus of pulmonary embolism, color and spectrum Doppler can dynamically show the relationship between blood flow and tumor echo in stenosis, and can detect blood velocity. Color echocardiography is of great value in the diagnosis, differential diagnosis and postoperative follow-up of pulmonary artery sarcoma.

\section{Treatment}

At present, it is agreed that surgical resection of tumor is the first choice of treatment for pulmonary intimal sarcoma, To completely clear the lesion, this method can prolong the survival time; The role of radiotherapy and chemotherapy is controversial, but there is a tendency for surgery combined with chemotherapy and/ or radiotherapy, especially for those who cannot complete surgical resection or recurrence after surgery, more recommended to try; $20 \%$ of patients responded better to chemotherapy or radiotherapy. Prognosis of primary pulmonary intimal sarcoma is poor; tumor can be transferred to brain, pancreas, adrenal gland, lung. A life expectancy of 12-18 months after symptoms, the 1-year and 2 -year survival rates were 22 and $7 \%$, respectively. The median survival of patients unable to operate due to disease progression (progressive right heart failure) was 
only 6 weeks, the survival time of patients with surgical resection can be up to 3 years [7-17].

\section{Conclusion}

Pulmonary artery intimal sarcoma is similar to the diseases of thromboembolism clinically. It is very important to differentially diagnose these two diseases because of the different treatment options and prognosis. Pathological diagnosis is the ultimate diagnosis.

\section{Abbreviations}

PAS: Pulmonary artery intimal sarcoma; CTA: Computed tomography angiography; CDFI: Color Doppler flow imaging.

\section{Acknowledgements}

The author thanks BXF for the echo illustration and excellent work in typing the manuscript. The author also thanks RLT for the revision of the manuscript. Both the authors read and approved the final manuscript.

\section{Authors' contributions}

BXF: drafted the manuscript, contributed to data and images collection; RLT: provided consultation, participated in the design and coordination of the manuscript. Both the authors read and approved the final manuscript.

\section{Funding}

Not applicable.

\section{Availability of data and materials}

All data generated or analyzed during this study are included in this published article.

\section{Declarations}

Ethics approval and consent to participate Not applicable.

\section{Consent for publication}

Written informed consent was obtained from the patient's next to kin for the publication of this case report and any accompanying images. A copy of the written consent is available for review by the Editor of this journal.

\section{Competing interests}

The authors have no funding, financial relationships, or competing interests to disclose.

Received: 29 June 2021 Accepted: 9 July 2021

Published online: 09 August 2021

\section{References}

1. Xu R, Zhao $Y, X u X$, et al. Pulmonary intimal sarcoma involving the pulmonary valve and right ventricular outflow tract: a case report and literature review. Medicine. 2020;99(3):e18813.

2. Ding-Yu C, et al. Pulmonary artery intimal sarcoma: a case report and literature review. Respirol Case Rep. 2020;8(2):e00530.

3. Ushioda $\mathrm{R}$, Kitahara $\mathrm{H}$, Ise $\mathrm{H}$, et al. A case of pulmonary artery sarcoma that was initially mis-diagnosed as pulmonary embolism. J Surg Case Rep. 2019;2019(3):rjz078.

4. Yeungd F, Johnston A, Simmons $C$, et al. Multimodality imaging of a pulmonary artery sarcoma. Echocardiography. 2018;35(1):123-5.

5. Lee $\mathrm{Y}$, Kimh J, Yoon $\mathrm{H}$, et al. Clinical characteristics and treatment outcomes of primary pulmonary artery sarcoma in Korea. J Korean Med Sci. 2016;31(11):1755-60.

6. Drozdz J, Warcho E, Fijuth J, et al. Primary pulmonary artery sarcoma in 36-year-old women: 3-years follow-up after partial resection and radiotherapy. Kardiol Pol. 2013;71(8):858-60.

7. Long $\mathrm{HQ}$, Qin $\mathrm{Q}$, Xie $\mathrm{CH}$. Response of pulmonary artery intimal sarcoma to surgery, radiotherapy and chemotherapy: a case report. J Med Case Rep. 2008;2:217.

8. Wilkens $\mathrm{H}$, Konstantinides $\mathrm{S}$, Lang I, et al. Chronic thromboembolic pulmonary hypertension: recommendations of the cologne consensus conference 2016. Dtsch Med Wochenschr. 2016;141(S1):S62-9.

9. Srivali N, Yie S, Ryu JH. Pulmonary artery sarcoma mimic king pulmonary embolism: a case series. QJM. 2017;110(5):283-6.

10. Yin K, Zhang Z, Luo R, et al. Clinical features and surgical outcomes of pulmonary artery sarcoma. J Thorac Cardiovasc Surg. 2018;155(3):1109-15.

11. Deng L, Zhu J, Xu J, et al. Clinical presentation and surgical treatment of primary pulmonary artery sarcoma. Interact Cardiovasc Thorac Surg. 2018;26(2):243-7.

12. Yamamoto $Y$, Shintani $Y$, Funaki S, et al. Aggressive surgical resection of pulmonary artery intimal sarcoma. Ann Thorac Surg. 2018;106(4):e197-9.

13. Wyler Vonballmoos MC, Chan EY, Reardon MJ. Imaging and surgical treatment of primary pulmonary artery sarcoma. Int J Cardiovasc Imaging. 2019;35(8):1429-33.

14. Morreau SP, Haydock DA. Prolonged survival of pulmonary artery sarcoma after aggressive surgical resection. Ann Thorac Surg. 2017;103(1):e21-3.

15. Jenkins DP, Madani M, Mayer E, et al. Surgical treatment of chronic thromboembolic pulmonary hypertension. Eur Respir J. 2013;41(3):735-42.

16. Gan HL, Zhang JQ, Zhou QW, et al. Surgical treatment of pulmonary artery sarcoma. J Thorac Cardiovasc Surg. 2011;142(6):1469-72.

17. Yamasaki M, Sumi Y, Sakakibara Y, et al. Pulmonary artery leiomyosarcoma diagnosed without delay. Case Rep Oncol. 2011;4(2):287-98.

\section{Publisher's Note}

Springer Nature remains neutral with regard to jurisdictional claims in published maps and institutional affiliations.
Ready to submit your research? Choose BMC and benefit from:

- fast, convenient online submission

- thorough peer review by experienced researchers in your field

- rapid publication on acceptance

- support for research data, including large and complex data types

- gold Open Access which fosters wider collaboration and increased citations

- maximum visibility for your research: over 100M website views per year

At BMC, research is always in progress.

Learn more biomedcentral.com/submissions 